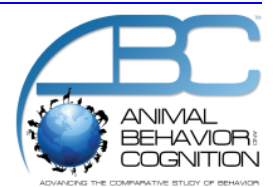

\title{
Slow Progress with the Most Widely Used Animal Model: Ten Years of Metacognition Research in Rats, 2009-2019
}

\author{
Victoria L. Templer
}

Department of Psychology, Providence College

*Corresponding author (Email: vtempler@providence.edu)

Citation - Templer, V. L. (2019). Slow progress with the most widely used animal model: Ten years of metacognition research in rats, 2009-2019. Animal Behavior and Cognition, 6(4), $273-277$. https://doi.org/10.26451/abc.06.04.07.2019

\begin{abstract}
Until recently, demonstrations of metacognition in primates have been frequent and robust, while in rodents they have been few and equivocal. However, the past few years have seen a change in this trend with the introduction of novel methods to determine whether metacognitive responding is governed by internal or external sources of stimulus control in rats. Such studies suggest that like primates, rats can indeed use internal assessment of memory strengths to guide metacognitive responding. Strong behavioral paradigms suitable for rodents support the development of easily-accessible animal models for the neurobiology of metamemory and translational studies on diseases of memory. They also allow for a more complete comparative study of the evolution of metacognition, as the presence of this ability in rodents would suggest that metacognition evolved $\sim 80$ rather than $\sim 25$ million years ago.
\end{abstract}

Keywords - Metamemory, Memory awareness, Monitoring, Declarative memory, Explicit memory, Rodent

In a 2009 special issue on metacognition in Comparative Cognition \& Behavior Reviews (CCBR), leaders in the field reviewed the literature to date on the ability of nonhuman animals to think about thinking (Crystal \& Foote, 2009; Hampton, 2009a, 2009b; Jozefowiez, Staddon, \& Cerutti, 2009; Smith, Beran, Couchman, Coutinho, \& Boomer, 2009). For the most part, everyone agreed: alternative explanations can often explain putative metacognition. For example, after reviewing the last 15 years of research on metacognition in nonhuman animals, Hampton (2009b) concluded that many demonstrations of metacognitive responding could be explained by associative learning or other mechanisms in which the stimulus guiding metacognitive responding is external rather than internal, private, or introspective. There were a few demonstrations of metacognitive responding, however, that were mostly immune to these criticisms, including situations in which the metacognitive choice was made prior to the primary task, the discriminada was mnemonic, and multiple generalization tests were run (e.g., Hampton, 2001; Smith, Redford, Beran, \& Washburn, 2006). Since then, and perhaps driven by the call for "sharper paradigms and safer inferences" (Smith, Beran, Couchman, \& Coutinho, 2008), evidence for introspective metacognitive behavior in which alternative mechanisms can be ruled out has mounted, with the most robust evidence coming from work with primates (e.g., Basile, Schroeder, Brown, Templer, \& Hampton, 2015; Beran, Smith, \& Perdue, 2013; Brown, Basile, Templer, \& Hampton, 2019; Call, 2010; Smith et al., 2018; Templer, Brown, \& Hampton, 2018).

In 2009 we were not sure if rats were capable of internally-guided metacognitive responding. Crystal's group had recently published the first study investigating the possibility of metacognitive responding in rats, which showed that in a perceptual task, rats adaptively declined difficult trials (Foote \& Crystal, 2007). Subjects were required to make the metacognitive choice before the psychophysical 
discrimination, thereby preventing behavioral cues, such as response latencies or vacillating, and ruling out that response competition alone was guiding behavioral responding (see Hampton, 2009b, for detailed explanations of mechanisms for metacognitive responding). While the results of this initial study were promising and exciting, the new way of examining metacognition after the 2009 CCBR discussion created many new questions that remained unanswered. Firstly, the fact that the task did not involve generalization tests to novel stimuli left open the possibility that subjects could have used external cues in the environment to guide metacognitive responding, such as associating cue delay length with declining the test (Hampton, 2009b). Secondly, at this same time, quantitative models based on response-strength and reinforcement were proposed that mirrored the cognitive behavioral explanations Hampton proposed as external sources of stimulus control. These models (Le Pelley, 2012; Smith et al., 2008) could explain adaptive use of the decline response and the Chosen-Forced performance advantages shown by Crystal's rats without invoking cueing by internal cues (Crystal \& Foote, 2009, 2011).

Since that time, a few more attempts were made to determine if rats were indeed capable of metacognitive responding, but few efforts have been made to dissociate potential sources of internal or external stimulus control. Expanding upon the paradigm in which rats classified tone durations as either long or short, rats were sometimes allowed to repeat the stimulus and were sometimes forced to hear it again (Foote \& Crystal, 2012). Less than half of the rats were more accurate at making the duration discrimination when they were forced to repeat it than when they chose to repeat it, and rats were not more likely to repeat the stimulus on difficult trials. Moreover, the authors were unable to eliminate the possibility that rats learned to associate intermediate durations with trial-decline responses. Mixed results were collected by other groups that also failed to test rats on generalization tests that could have tested for the possibility of environmental cue associations (Kirk, McMillan, \& Roberts, 2014).

More recently, one group did test for generalization of metacognitive responding and found that rats used the decline response when the sample in the delayed-match-position tests was omitted. Importantly, adaptive use of the decline response was only obtained when the test was at the optimal level of difficulty (six-choice task) but not when the task was relatively easy (two-choice task), and the resulting utility of declining trials was low (Yuki \& Okanoya, 2017). Indeed, students of metacognition often appropriately titrate difficulty level during training so that subjects experience uncertainty or forgetting; performance on the primary task should be above chance but below ceiling, so that use of the decline response has the opportunity to be advantageous (e.g., Brown, Templer, \& Hampton, 2017; Hampton, 2001; Templer, Lee, \& Preston, 2017). Nonetheless, evaluating the utility of metacognitive judgments has led to fruitful results, especially in elucidating the neural mechanisms underlying them in humans (Yuki, Nakatani, Nakai, Okanoya, \& O.Tachibana, 2019).

While Yuki and Okanoya (2017)'s findings certainly progressed the field of rodent metacognition, results consistent with metacognitive responding were presented with just two rats in one generalization test. Since the extent to which rats demonstrate metacognitive responding remained an open question, we aimed to answer questions about whether potential metacognitive responding is governed by internal or external sources of stimulus control in a large cohort of rats that was given multiple generalization tests (Templer et al., 2017). We developed a new paradigm (Lee, Preston, Wise, \& Templer, 2018) for testing metacognition in rats that was adapted after existing paradigms in primates (Hampton, 2001; Templer \& Hampton, 2012). Positive results in an olfactory-based delayed matching-tosample (DMTS) task with nine rats clarified that even when environmental (external) contingencies were inconsistent and could not serve as discriminative cues, rats transferred adaptive use of the decline response. All nine subjects continued to selectively utilize the decline response when memory was weak or nonexistent and refrained from using it when memory was strengthened. This pattern suggested that rats used an internal assessment of memory strength to guide responding in this task.

This most recent study in rats adds a critical piece to the phylogenetic picture of the evolution of metacognition across species (Templer et al., 2017) and provides us with a better understanding that rats are capable of guiding behavior based on cognitive and memory awareness. Humans share a common ancestor with rats that existed approximately 80 million years ago (Gibbs et al., 2004) while the common ancestor between humans and Old World monkeys existed about 25 million years ago (Stevens et al., 
2013). Positive demonstrations of internal cues or memory states guiding metacognitive responding in Old World monkeys are both frequent and robust, and while worth doing and informative, the field of nonhuman metacognition would also benefit greatly if we could answer more questions about the more distant evolution of metacognitive abilities. Using rodents has this advantage given that we are more distantly related. Recent studies in other species such as pigeons (Iwasaki, Watanabe, \& Fujita, 2018) have added to this picture and point to the possibility of convergent evolution.

Metamemory, a type of metacognition, is the ability to access and monitor the contents of one's memory, a hallmark of the explicit or declarative memory system. Here, cognitive access of the explicit memory system and memory awareness do not necessitate a state of conscious awareness (e.g., Templer, 2016). Despite the fact that evidence is accumulating that rats have explicit memory systems that function at the same basic level as humans (Crystal \& Smith, 2014; Eacott \& Easton, 2010; Eichenbaum, 2011; Panoz-Brown et al., 2016, 2018), progress in the field of rat metamemory has been relatively slow. This might be due to the fact that finding a paradigm suitable for rats has been difficult and the sensory modality has varied widely across tasks (auditory: Foote \& Crystal, 2007, 2012; visual: Kirk et al., 2014; Yuki \& Okanoya, 2017). It is worth noting that the most robust results were obtained from a task that used odor as the discriminada (Templer et al., 2017), so future research endeavors might benefit from such ecologically relevant stimuli and testing procedures (Lee et al., 2018). However, titrating individual performance on the primary memory task such that subjects forget about $30-40 \%$ of the time is laborintensive, especially in a non-automated task. Future studies may, therefore, benefit from using an automated olfactory-based task, such as a match-to-sample procedure in an operant box (e.g., Lu, Slotnick, \& Silberberg, 1993).

Using rodents in the comparative study of metacognition has the considerable benefit of creating a better model of cognitive accessibility and memory function and dysfunction in the most commonly used animal model. Such an easily accessible animal model readily lends itself to neurobiological investigation, which is critical to uncovering neurobiological underpinnings of complex cognition and memory awareness that degrade in diseases of memory and old age. Hopefully, the next ten years will bring faster progress in the field of rodent metacognition with focus on examining multiple sources of stimulus control and combining cognitive behavioral manipulations with neurobiological techniques (Templer, 2016; Templer \& Hampton, 2013). Future data from rodents would be especially compelling if we focus on dissociating the source of internal cues, such as working memory, ease of processing, familiarity, and heuristic cues, as researchers have recently begun to study and in some cases dissociate in monkeys (Brown et al., 2019; Ferrigno, Kornell, \& Cantlon, 2017; Kornell, 2014). Such studies will inform the evolution of metacognition in crucial ways and will provide a necessary model for better understanding the neurobiology of cognitive control and memory awareness.

\section{Acknowledgements}

The author would like to thank Reggie Paxton Gazes for reviewing a draft of this paper.

\section{References}

Basile, B. M., Schroeder, G. R., Brown, E. K., Templer, V. L., \& Hampton, R. R. (2015). Evaluation of seven hypotheses for metamemory performance in rhesus monkeys. Journal of Experimental PsychologyGeneral, 144, 85-102.

Beran, M. J., Smith, J. D., \& Perdue, B. M. (2013). Language-trained chimpanzees (Pan troglodytes) name what they have seen but look first at what they have not seen. Psychological Science, 24, 660-666.

Brown, E. K., Basile, B. M., Templer, V. L., \& Hampton, R. R. (2019). Dissociation of memory signals for metamemory in rhesus monkeys (Macaca mulatta). Animal Cognition, 22, 331-341.

Brown, E. K., Templer, V. L., \& Hampton, R. R. (2017). An assessment of domain-general metacognitive responding in rhesus monkeys. Behavioural Processes, 135, 132-144.

Call, J. (2010). Do apes know that they could be wrong? Animal Cognition, 13, 689-700. 
Crystal, J. D., \& Foote, A. L. (2009). Metacognition in animals. Comparative Cognition and Behavior Reviews, 4, $1-16$.

Crystal, J. D., \& Foote, A. L. (2011). Evaluating information-seeking approaches to metacognition. Current Zoology, 57, 531-542.

Crystal, J. D., \& Smith, A. E. (2014). Binding of episodic memories in the rat. Current Biology, 24, 2957-2961.

Eacott, M. J., \& Easton, A. (2010). Episodic memory in animals: Remembering which occasion. Neuropsychologia, $48,2273-2280$.

Eichenbaum, H. (2011). The cognitive neuroscience of memory: An introduction (2 ${ }^{\text {nd }}$ ed.). Oxford: Oxford University Press.

Ferrigno, S., Kornell, N., \& Cantlon, J. F. (2017). A metacognitive illusion in monkeys. Proceedings of the Royal Society B-Biological Sciences, 284, 20171541.

Foote, A. L., \& Crystal, J. D. (2007). Metacognition in the rat. Current Biology, 17, 551-555.

Foote, A. L., \& Crystal, J. D. (2012). "Play it again": A new method for testing metacognition in animals. Animal Cognition, 15, 187-199.

Gibbs, R. A., Weinstock, G. M., Metzker, M. L., Muzny, D. M., Sodergren, E. J., Scherer, S.,...Woodage, T. (2004). Genome sequence of the Brown Norway rat yields insights into mammalian evolution. Nature, 428, 493521.

Hampton, R. R. (2001). Rhesus monkeys know when they remember. Proceedings of the National Academy of Sciences of the United States of America, 98, 5359-5362.

Hampton, R. R. (2009a). Focusing the uncertainty about nonhuman metacognition. Comparative Cognition and Behavior Reviews, 4, 56-57.

Hampton, R. R. (2009b). Multiple demonstrations of metacognition in nonhumans: Converging evidence or multiple mechanisms? Comparative Cognition and Behavior Reviews, 4, 17-28.

Iwasaki, S., Watanabe, S., \& Fujita, K. (2018). Pigeons (Columba livia) know when they will need hints: Prospective metacognition for reference memory? Animal Cognition, 21, 207-217.

Jozefowiez, K., Staddon, J. E. R., \& Cerutti, D. T. (2009). Metacognition in animals: How do we know that they know? Comparative Cognition and Behavior Reviews, 4, 29-39.

Kirk, C. R., McMillan, N., \& Roberts, W. A. (2014). Rats respond for information: Metacognition in a rodent? Journal of Experimental Psychology: Animal Behavior Processes, 40, 249-259.

Kornell, N. (2014). Where is the "meta" in animal metacognition? Journal of Comparative Psychology, 128, 143149.

Le Pelley, M. E. (2012). Metacognitive monkeys or associative animals? Simple reinforcement learning explains uncertainty in nonhuman animals. Journal of Experimental Psychology: Learning Memory and Cognition, $38,686-708$.

Lee, K. A., Preston, A. J., Wise, T. B., \& Templer, V. L. (2018). Testing for metacognitive responding using an odor-based delayed match-to-sample test in rats. Journal of Visualized Experiments, 136, e57489.

Lu, X.-C. M., Slotnick, B. M., \& Silberberg, A. M. (1993). Odor matching and odor memory in the rat. Physiology \& Behavior, 53, 795-804.

Panoz-Brown, D., Corbin, H. E., Dalecki, S. J., Gentry, M., Brotheridge, S., Sluka, C. M.,...Crystal, J. D. (2016). Rats remember items in context using episodic memory. Current Biology, 26, 2821-2826.

Panoz-Brown, D., Iyer, V., Carey, L. M., Sluka, C. M., Rajic, G., Kestenman, J.,...Crystal, J. D. (2018). Replay of episodic memories in the rat. Current Biology, 28, 1628-1634.

Smith, J. D., Beran, M. J., Couchman, J. J., \& Coutinho, M. V. C. (2008). The comparative study of metacognition: Sharper paradigms, safer inferences. Psychonomic Bulletin \& Review, 15, 679-691.

Smith, J. D., Beran, M. J., Couchman, J. J., Coutinho, M. V. C., \& Boomer, J. B. (2009). Animal metacognition: Problems and prospects. Comparative Cognition and Behavior Reviews, 4, 40-53.

Smith, J. D., Boomer, J., Church, B. A., Zakrzewski, A. C., Beran, M. J., \& Baum, M. L. (2018). I scan, therefore I decline: The time course of difficulty monitoring in humans (Homo sapiens) and macaques (Macaca mulatta). Journal of Comparative Psychology, 132, 152-165.

Smith, J. D., Redford, J. S., Beran, M. J., \& Washburn, D. A. (2006). Dissociating uncertainty responses and reinforcement signals in the comparative study of uncertainty monitoring. Journal of Experimental Psychology: General, 135, 282-297. 
Stevens, N. J., Seiffert, E. R., O'Connor, P. M., Roberts, E. M., Schmitz, M. D., Krause, C.,...Temu, J. (2013). Palaeontological evidence for an Oligocene divergence between Old World monkeys and apes. Nature, 497, 611-614.

Templer, V. L. (2016). Episodic memory. In V. Weekes-Shackelford, T. K. Shackelford, \& V. A. WeekesShackelford (Eds.), Encyclopedia of Evolutionary Psychological Science (pp. 1-4). Cham: Springer International Publishing.

Templer, V. L., Brown, E. K., \& Hampton, R. R. (2018). Rhesus monkeys metacognitively monitor memories of the order of events. Scientific Reports, 8, 11541.

Templer, V. L., \& Hampton, R. R. (2012). Rhesus monkeys (Macaca mulatta) show robust evidence for memory awareness across multiple generalization tests. Animal Cognition, 15, 409-419.

Templer, V. L., \& Hampton, R. R. (2013). Episodic memory in nonhuman animals. Current Biology, 23, R801R806.

Templer, V. L., Lee, K. A., \& Preston, A. J. (2017). Rats know when they remember: Transfer of metacognitive responding across odor-based delayed match-to-sample tests. Animal Cognition, 20, 891-906.

Yuki, S., Nakatani, H., Nakai, T., Okanoya, K., \& O.Tachibana, R. (2019). Regulation of action selection based on metacognition in humans via a ventral and dorsal medial prefrontal cortical network. Cortex, 119, 336-349.

Yuki, S., \& Okanoya, K. (2017). Rats show adaptive choice in a metacognitive task with high uncertainty. Journal of Experimental Psychology: Animal Learning and Cognition, 43, 109-118. 